\title{
The RFad Method - a new fatigue recovery time assessment for industrial activities
}

\author{
Marcello Silva e Santos ${ }^{\mathrm{a},{ }^{* 1}}$, Mario Cesar Rodriguez Vidal ${ }^{\mathrm{b}}$ and Sergio Bastos Moreira ${ }^{\mathrm{c}}$ \\ ${ }^{a}$ Industrial Engineering Department, UNIFOA, University Complex of Volta Redonda, , Av. Paulo Erlei Alves \\ Abrantes, $n^{\circ} 1325$, Três Poços, Volta Redonda,RJ. CEP: 27240-560, Brazil, \\ ${ }^{b}$ GENTE/COPPE Ergonomics Laboratory - Federal University of Rio de Janeiro, Av. Horacio de Macedo 2030, \\ Bloco G Sl 207, CEP 21941-914, Cidade Universitaria, Rio de Janeiro, RJ, Brazil \\ ${ }^{c}$ Physiology Department, UNIFA, Air Force University, Av. Marechal Fontenelle, 1200, Campo dos Afonsos, CEP \\ 21740-000, Rio de Janeiro, RJ, Brazil.
}

\begin{abstract}
This paper presents a study about fatigue recovery time assessment processes in work activities. It came about due to a demand presented by an automotive industry giant, in need of updating existing cycle time sheets and TAKT time parameters. The company decided to hire an Ergonomics Laboratory with ties to a major Brazilian University in order to evaluate current conditions and establish a new method to either calculate recovery times or validate existing assessment criteria, based in the ergonomics evaluation of the work activities. It is clear that there has been evident evolution in the industrial sector in the past two decades. It brought up fast modernization of industrial processes, not only in production but also in terms of management systems. Due to improved computer and robotics systems, combined with overall operational advancements - like the use of lighter hand tools and more effective hoist systems - most work activities have had its physical effort requirements reduced in the past decades. Thus, compensation factors built into production times need to be reviewed in order to avoid unnecessary costs associated to them. By using ergonomics considerations, we prevent simply removing the physical variables built in rest time calculations without taking on account, for example, additional cognitive load represented by the use of more sophisticated pieces of equipment.
\end{abstract}

Keywords: applied ergonomics, organizational design \& management, industrial ergonomics

\section{Introduction}

The origin of the discussions in this article was brought up by the Planning Department of an automotive company based in São Paulo, Brazil. They had decided to reevaluate current cycle time methods, especially the criteria used to estimate supplemental times. Those allowances are added - in the form of percentages - to the total expected time for completion of a determined work activity and the combined time converge into production TAKT times.

There are many factors that contribute to the workload experienced by individuals at work. Factors include the nature of the work, somatic aspects, acquired training, motivation, and environmental influence. If work conditions improve, the workload tends to be reduced, even though it may not happen immediately for the work pace takes time to be adjusted. However, after a set of technological improvements has been implemented for some time, it makes no sense to keep using the same cycle times and planning methods that were designed under other reality without calibrating the data.

Thus, initially the goal was to verify and validate the appropriateness of existing fatigue allowance criteria in cycle time sheets. There are many factors that contribute to the workload experienced by individuals at work. Factors include the nature of the work, somatic aspects, acquired training, motivation, and environmental influence. These factors affect energy throughput through the physiological service function of supplying power and oxygen for muscle

\footnotetext{
${ }^{1}$ Corresponding author. Email: marcellosanto@hotmail.com
} 
metabolism. If work conditions improve, the workload tends to be reduced, even though it may not happen immediately for the work pace takes time to be adjusted. However, after a set of technological improvements has been implemented for some time, it takes no sense to keep using the same cycle times and planning methods that were designed under other reality without calibrating the data. The least to be done is to verify the validity of such data to avoid planning and production distortions.

As the main contradictory factor amongst supplemental times, the concept of fatigue and its consequences have substantially evolved. In the past restricted in the physical domain, fatigue today is viewed in a much broader sense. It is understood as a complex biological response mechanism, in which metabolic rates, muscular skeletal compromise, workload and all sorts of kinetics, mental and sensorial responses converge and interact in an integrative manner.

[4] Grandjean (2005) uses an analogy in which he compares fatigue with a tank receiving all sorts of different liquid influx, representing physical loads, environmental constraints, mental distress and so on. Before the tank overflows, one needs to open a relieve valve to let some "fatigue mix" out, before the person becomes incapacitated. [3] Carayon (1993) and [14] Santos (2010) relate fatigue to the work environment that must be balanced to prevent fatigue.

The method presented in this paper follows a linear explanatory guideline. Fist, we expose the background that justify and provides support the method formulation, with historical, legal and physiological considerations about fatigue and work time measurements. Then, a synthesis of the Rfad method is described, enumerating the characteristics of the construct, definition of study variables, the choice of formulas and other details. In the next step we show the preliminary results from which we drew our initial conclusions. At last, we discuss current status and propose future actions in order to consolidate the method and establish strategies to have it incorporated into industrial planning procedures.

\section{Background}

The GENTE/COPPE Laboratory, an important Ergonomics Research \& Development organization with ties to the Federal University of Rio de Janeiro, was invited by a major automotive company to participate in a breakthrough study. This innovative cha- racter relates to a joint effort to establish adequate measurement techniques, considering both ergonomics and operational planning and programming procedures in its formulation. In fact, it all boils down to whether fatigue recovery is properly considered in current time tables, used by the plant's operational planners.

Currently, planners determine or reevaluate production TAKT-times based upon the use of time sheets. The cycle times are a mix of operational and non-operational work times. The so called supplementary times - fatigue recovery included - are considered in the total cycle time by means of percentage inputs to standard times.

\subsection{Generic considerations on fatigue issues}

It is undeniable that Ergonomics and Industrial planning are related and interdependent issues. In the beginning of the 20th century, several researchers and practitioners identified constraints posed by working conditions when trying to establish fair estimates for work time cycles. [11]Murrell (1969), who designed a formula to determine whether a particular task should have a planned rest based on energy consumption, note that workers prefer short and more frequent breaks than a long pause. The reason for that may not be exclusively for fatigue remediation. The fact is that fatigue started to be an area of interest for both physiologists and industrial engineers [13] (Sanders \& Mc Cormick, 1993), which brought alone some controversy regarding the nature of human fatigue and mandatory rest time for its effects.

For either lack of knowledge, regulations or compromise - or a bit of all of those - industrial planners did not pay much attention to shop floor reality when building up their time cycle sheets. As a result, some sort of a pondered chrono analysis - with the use of fix rates for non-productive times - became quite a standard approach for establishing task time cycles, leaving behind a trail of unrealistic production goals for factory workers.

Some authors are skeptical as to the effectiveness of quasi-scientific methods for work measurement. [7] Johnson \& Kaplan (1987), say that from an economic-rationalist viewpoint, operations managers "focus their attention on predetermining "standard" rates at which material and labor should be consumed in manufacturing tasks." The methods they devised to determine standards for material and labor inputs included deterministic, direct and objective engineering design of bills of material, on one hand, and those 
always subjective - sometimes imprecise - time and motion studies [2] Barnes, (1980).

Consequently, the assumption of complexity in fatigue measurements led to the adoption of rough estimating - of fatigue compensation - as the most utilized form of accounting for recovery times in the case of adverse work conditions. However, it is likely that some parameters have been generously inflated by industrial planners, especially during the eighties [15] (Silver, 2003).

About 30 years ago, manufacturing workers reached a highly privileged position in terms of their importance in the capital and work balance [5] (Keohane, 1984). Yet today, people tend to disagree more than to convey views in relation to what fatigue really is, what triggers it (and why), how it is determined and whether it should or should not be considered in cycle time determination or reformulation. Moreover, it involves legal, normative exigencies but also physiological (which includes psychological aspects) considerations in order for it to be considered in the process of operations management. Therefore, we should to combine it all into a consistent method in which both regulatory needs and physiological requirements can coherently coexist.

As industrial relations improved in the Industrial world and the positive effects of internationalization spread out around the globe, new labor legislation and safety measures started to take place everywhere [8] Lung (2000). A wave of new concerns came along in the trail of those changes, pushing companies to redesign their traditional methods, including those related to production planning. However, most of those changes were limited to the hazardous work standards, set forth by occupational and safety requirements related to the various aspects of work activities. In other words, industrial planning was free to set time cycles and rest pauses, as long as the worker could handle the tasks without dying or becoming incapacitated. Alternatively, they could apply fictitious rates to compensate for work overload or physical constraints present in the work activities.

Of course, none of those options were recommended as best practice, especially under what is viewed today as Industry's best practices. Thus, new methods became needed to assess fatigue and properly allocate time windows for work rest cycles. Discussing the emergence and the characteristics of those methods is not part of our scope, however it is important to cite our context. In Brazil, manufacturers and service providers have to follow a set of regulations determined by the Ministry of Labor. The so called Regulatory Standards, have two specific chap- ters of interest for ergonomists: The NR.15 and NR. 17.

The NR-15 regulation deals with Hazardous and Unsafe Conditions in the work environment. The NR-17 on its turn addresses ergonomics issues in the workplace. The only reference as to whether fatigue standards are measured or monitored is indirect. It appears in terms of limitations regarding repetitive tasks to avoid RSD and some tables showing metabolic rates for energy expenditure in selected activities.

\subsection{Physiological considerations in fatigue measurements - theory and practice}

The most important issue on predicting fatigue or fatigue mitigation is the role of physiology as both part of the problem and the source of responses. We become fatigued by overloading our muscular skeletal apparatus during work activities. For overcoming fatigue, we must rest the group of overloaded muscles for a period of time, allowing for adequate sufficient recovery. In order to establish the correct amount of time necessary for the work cycle rest, we need to apply physiological evidence, such as energy expenditure, metabolic rates and aerobic capacity. According to [7]Johnson \& Kaplan (1987), the choice of measurement technique is determined by the objective of the assessment, the resources available and the ability and willingness of the subjects to partake.

[1] Ästrand \& Rodhal (1984) and [9]Monod (1994) amongst others note that human being's performance is limited to $40 \%$ of his maximum oxygen intake (VO2max). Therefore, the use of plain worksheets without compensation for individual variations - is a mere abstraction with no practical result. However, in some cases - like the one we had in hand - the use of sample sets for population and arbitration of physical characteristics for an "average worker", is the only possible way to conduct an experiment involving aerobic capacity, fatigue measurement or work rest cycles at the shop floor. The VO2max considered for the study was the mean value for workers in the 45 selected workstations; It was calculated by using [6] Jackson, A. et al (1988) technique, in which answers to a questionnaire called FF (Fitness Factor) initially turned out the aerobic index for each worker. The value was combined with the BMI, weight and height of each individual. This was then tallied up so that we could extract the mean value to be used in the formula. 
Likewise, some other decisions in terms of different ways for carrying out the study were motivated by non-technical issues. The adoption of noninvasive techniques, for example, happened because of two different reasons. The first one related to the nature of the operations, which prohibited interruption of the activities - or poor mobility - imposed by invasive techniques. Secondly, because the use of measurement apparatus - especially those based in determining oxygen consumption - would affect the outputs for that particular task. Therefore, even though those biomechanical and physiological measurement techniques are knowingly more effective at least quantitatively speaking - opting out to qualitative, more subjective techniques and methods proved, nonetheless, more adequate in our context.

We employed a formula proposed by Jackson et al., which combines individual data and qualitative parameters. We had to rely on data previously collected by the health department and average it out to estimate the VO2max. We came out with an average height of $1,73 \mathrm{~m}$ and average weight of 80,5 for men and $1,60 \mathrm{~m}$ and $66,6 \mathrm{~kg}$, respectively, for women. The BMI was set in 26,9 for men and 26,02 for women. The results for the FF questionnaire [12] (Moreira, 2010), applied by the Ergonomics team, turned out the mean value of 3 , for both men and women. The estimates were separated by gender.

Because the hazardous limitations and expenditure tables on the NR 15 standard are ser in kilocalories, we had to adjust Jackson's VO2max equations originally set in ml.kg-1.min-1 - to kcal.kg-1.min-1, expressing the Maximum Aerobic Power (MAP) for each group of worker. As we were working with mean values, based on pre-collected medical data, we found natural to find an average weight (for men) of around $80 \mathrm{~kg}$. Thus, we decided to use a $95 \%$ confidence interval and our reasoning was carried out following this conceptual referential. Under this approach, we found an average energy expenditure between 0,4111 and $0,4319 \mathrm{kj} \cdot \mathrm{kg}-1 \cdot \mathrm{min}-1$ (approximately 0,098 to $0,1 \mathrm{kcal} . \mathrm{kg}-1 . \mathrm{min}-1$ ) for a body mass of $80,1 \mathrm{~kg}$, which produces the equivalent to 1,6 e 1,7 liters per minute, in terms of oxygen consumption or a MAP of between 7 and $7,4 \mathrm{~W} / \mathrm{kg}$.

If we consider the limitation set by the equation of $40 \%$, as to the maximum oxygen intake of an individual for a 8 work hour per day shift, the ideal PAM figures should be around $18 \mathrm{~W} / \mathrm{kg}$. It represents a maximum oxygen intake between 50 e $53 \mathrm{ml}$. kg1.min-1. Based on those numbers and considering only the physiological aspects, our study for the sample of workstation returned a maximum workload equivalent to 463 minutes, with a rest time set in 17 minutes. In other words, in order to sustain adequate levels of performance, for each 7,7 hours of continuous work a person must rest 0,3 hours, which certainly happens throughout the shift, considering rest allowances, micro-pauses and other work breaks. However, we had to deal with this subject in a broader vision in order to satisfy all involved stakeholders.

Although oxygen consumption is directly related to energy expenditure, it is troublesome to be measured in a real-world work situation. Heart rate, which has correlation to oxygen consumption, can be used to estimate energy expenditure, but it is also tricky. First, the linear relationship between heart rate and energy expenditure is different for different people. It is proved that physical condition and aerobic power can lower the heart rate and, consequently, more fit individuals will not have to work as hard in order to provide oxygen to working muscles. Therefore, if we seek accuracy in energy measurements we need to: a) adjust the population data - to compensate for individual variance in terms of energy consumption and productivity levels; b) incorporate methodological trade offs - to compensate for data that cannot be collected properly, the latter being the main reason to employ applied ergonomics.

\section{Combining ergonomics and industrial planning - The Rfad method}

When our client, a major automotive industry in Brazil, decided to review its TAKT-time planning methods, the Industrial Planning department thought natural to invite an Ergonomics Laboratory to assume the task of developing a new method for assessing fatigue levels properly. With more accurate numbers, the amount of time allocated to fatigue recovery can become a more reliable variable to be computed into current time sheets. The decision of employing applied ergonomics had two major reasons: a) a natural ergonomics affinity to processes of physiology measurements and assessments b) the possibility of employing a "worker-friendly" strategy, more likely to be accepted by unions, occupational health department, workers commission and so forth.

Ergonomics is characterized as being a area of study in which every context is so particular to itself that it is hard to use recurrent formulas to respond to new demands. Consequently, it may sound as a paradox that this particularity is exactly what enables practitioners to come up with adequate solutions for 
every possible context. Initially, the lead research team established a multidisciplinary work group formed up by one physician, one architect, two engineers, two designers, one physiologist - all specialized in Ergonomics - and four other certified ergonomists. The team was divided in two groups: one for the field work activities and another responsible for data analysis, project management and coordination of activities along with the customer's project team.

As a way of characterizing the situation at hand, we decided to carry out a series of ergonomic analysis of work activities in selected workstations. Those 45 workstations were considered to be the most critical ones in the chosen manufacturing areas. We did not participate in the selection process, but we were told that decision was a consensual one amongst the main stakeholders (health, planning and production departments). At first we had an understanding that we were supposed to determine if those workstations - or the workers assigned to them - were under any kind of work overload or any physical or mental stress due to working conditions.

In a meeting requested by the health department, we realized that health records would not be necessary, since what we really needed to do was to find a way to quantify energy expenditure levels for the work activities, regardless of who was performing them. Since there was job rotation in all workstations, specific information would have been not only useless but rather distracting towards our goals.

In the process of our ergonomic demand validation, we came out with the basis for our method - the Rfad - for calculation of fatigue exposure and, if necessary, fatigue recovery times. Moreover, the identification of fatigue requirements were derived from the ergonomic analysis and fed in the criteria for calculating recovery time based on a series of variables built into the Rfad Method. In this sense, the resulting method became more than a formula to calculate rest time requirements. If used adequately, it may become a solid management tool to guarantee both ergonomics compliance and adherence to industrial planning logics. As a by product, it may also be used as a performance evaluation tool, since the main component in human productivity is work condition itself.

In our specific case, we had already conducted the ergonomic analysis and extracted information to build our performance indicators. We had also carried out the physiological testing to see whereas work activities were reasonably designed to avoid health hazards and production losses. But we still needed to combine Ergonomics in the method, trying to achieve a more realistic, coherent framework for the context and scope we had in hand. At the whole time, we were reminded that we had to guarantee appropriate work conditions whenever tweaking out programming sheets and removing any supplemental time. Those constraints helped to produce the second formula - a sequential procedure to the VO2max formula or equation - for the Rfad Method. We decided to adapt a formula proposed by Murrell (Apud McCormick, 1993). In fact, the main change we did was to use a constant denominator represented by a value close to the basic metabolic rate. The numerator was only adjusted to reflect the impact - or attenuation incurred by different variables that can affect energy expenditure and, consequently, rest time demands in the work activity.

The redesigned formula considers distinct situations of "ergonomic compromise", in terms of energy consumption and related to time directly applied in the particular work activity. This enables filters to prevent mishandling different data that should not be combined, such as levels of energy consumption for each operation. In easier terms, we tried to take in consideration the main factors that cause fatigue: a) muscular activity; b) ergonomic aspects (physiological and biomechanical demands, workstation and job design characteristics, environmental conditions, etc.); c) individual's physical and health factors. All those variables were converted into what we called "attenuation factors": Temperature, Aerobic Capacity, Ergonomic Criticality (SIC (C), Fitness Factor. The formula construct has the following aspect:

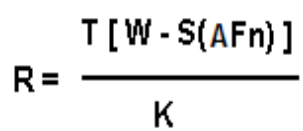

Being,

$\mathrm{R}=$ Rest Time (breaks or pauses) in minutes.

$\mathrm{T}=$ Time in between breaks (lunch, coffee, etc.).

$\mathrm{W}=$ Average Energy Expenditure at work in $\mathrm{Kcal} / \mathrm{min}$ (without attenuation factors).

$\mathrm{S}=$ Targeted Energy Expenditure at work in $\mathrm{Kcal} / \mathrm{min}$ (attenuation factors over plain table values). $\mathrm{AF}=$ Attenuation factors (GENTE Lab, 2010)

$\mathrm{K}=$ Constant of proportionality. Arbitrated at $\mathrm{K}=$ $1,5 \mathrm{Kcal} / \mathrm{min}$.

Some authors employ a variant of this formula. Instead of a constant, they consider the energy expenditure rate minus the recommended rate in the denominator. This would return an even shorter rest period. 


\begin{tabular}{|c|c|c|c|c|}
\hline Limits based on NR 15 Table & 25 & 292 & 3.67 & 5 \\
\hline Work shift Limits: & \multicolumn{4}{|c|}{ RESULTS BASED ON THE NATURE OF A TASK } \\
\hline $\begin{array}{c}\text { 4,78 }(\mathrm{kcal} / \mathrm{min}) \text { or } 0,06(\mathrm{~kg} / \mathrm{kg} / \mathrm{min}) \\
\text { VO2 Max: } 37,0(\mathrm{ml} / \mathrm{kg} / \mathrm{min}) \\
\text { MAP: } 13,92(\mathrm{kcal} / \mathrm{min}) \\
\text { Age: } 45 \text { anos BMI: } 26,9 \text { Total Body Mass: } 80,5 \\
\text { IAF: } 3 \text { Height: } 1,73 \mathrm{~m}\end{array}$ & D,031 & 0,0036 & $0,04 \%$ & $0,0,62$ \\
\hline $\begin{array}{c}\text { Work shift Limits: } \\
\text { 2,80 (kcal/min) or } 0,04(\mathrm{~kg} / \mathrm{kg} / \mathrm{min}) \\
\text { VO2 Max: } 25,5(\mathrm{ml} / \mathrm{kg} / \mathrm{min}) \\
\text { MAP: } 8,43(\mathrm{kcal} / \mathrm{min}) \\
\text { Age: } 45 \text { anos BMI: } 26,02 \text { Total Body Mass: } 66,6 \\
\text { IAF: } 3 \text { Height: } 1,60 \mathrm{~m}\end{array}$ & 0.038 & 0,044 & 0,055 & 0075 \\
\hline
\end{tabular}

Fig. 1. Excerpt of allowed limits based on task nature

\section{Calculations and initial results}

The study carried out in our case example must be considered a "work in progress". In fact, a postdoctoral fellowship is under way to investigate a series of implications, repercussions and future methodological opportunities raised up by the final project report of the original study. The findings may be summarized by the following: a) current work methods and technological resources alleviate muscular efforts in the majority of work activities in the shop floor; b) some work activities are less likely to be further improved - in terms of work conditions - due to the nature of some particular automotive industries (trucks, for example); c) Apparently, the use of outdated time sheets and planning methods in general is common practice in the industrial sector; d) Ergonomic work analysis is the most effective way for determining whether a particular work station needs recovery time due to fatigue.

When applying the VO2 Max formula, we could not find a single work activity requiring additional rest other than what is already allowed by management. By tweaking out the rates we started getting rest time needed only when women are involved in the tasks. In addition, when the Rfad formula was employed in selected workstations - for verification purposes only - we confirmed the inadequacy of considering additional rest periods, even when we input higher metabolic rates in the formula. The findings indicate that fatigue allowances should be reviewed to correct discrepancies and set takt-time to realistic figures.

The VO2 Max equation, adapted to our context by [12] Moreira (2010), could in theory suffice for determining the validity of rest allowances. However it would be more difficult to convince some of the stakeholders involved in the Project. As it turns out, it is consensual nowadays that fatigue cannot be evaluated only under physiological focus, which emphasizes the need to employ redundancy cross-checking as we propose. A table excerpt for the VO2Max evaluation at the selected 45 workstations is shown in Figure 1. By looking at the table we see that only in two of the selected workstations we find a need for pause.

Besides additional physiological considerations, there are environmental, psychological and design related inadequacies that may contribute to elevate or alleviate fatigue. In synthesis, we need to apply those factors to our fatigue recovery calculations. We decided to employ 4 attenuation factors (AF):

1) Effective temperature -from NR 15 tables.

2 Aerobic Condition - Drawn from the physiological study carried out with the workers.

3) Fitness Factor - Arbitrated after analysis of collected data and questionnaires.

4) Sum of Ergonomic Indicators Criticality (SIC) A proprietary measurement method by the GENTE Laboratory that assesses the degree of importance for ergonomic actions.

In fact, the SIC (C) index is itself a powerful prioritization tool for the ergonomic action, a step beyond the GUT Matrix, which is appropriated by the SIC Calculations (Figure 2). If we abstract all possible technical constraints and concentrate only in following on with the method application, let us take one example in which an activity passes the VO2 Max criteria. 


\begin{tabular}{|c|c|c|c|c|c|c|}
\hline Workstation & $\begin{array}{l}\text { Constraints } \\
\end{array}$ & Action & Standardization & Annotations & GUT Matrix & SIC \\
\hline \multirow{3}{*}{ C.C. 144.4} & $\begin{array}{l}\text { Awkward Postures as a result } \\
\text { of poor job design }\end{array}$ & & \multirow{3}{*}{$\begin{array}{l}\text { NR17.6.2. } \\
\text { a;b;c;d;e;f; } \\
\text { NR17.6.3.a;b;c }\end{array}$} & \multirow{3}{*}{9} & \multirow{3}{*}{839} & \multirow{3}{*}{120,816} \\
\hline & $\begin{array}{l}\text { Lack of protection device on } \\
\text { equipment may cause injury } \\
\text { of discomfort }\end{array}$ & & & & & \\
\hline & Above normal cognitive load & & & & & \\
\hline
\end{tabular}

Fig. 2. Example of SIC tool usage.

We will illustrate by using a scenario of a $240 \mathrm{mi}$ nutes work cycle and an activity with the following characteristics:

Activity Type : Stand up work, on workbench, moderate and with some mobility: $3,67 \mathrm{Kcal} / \mathrm{min}$ (according to NR 15 tables)

Effective Temperature: 26 IBUTG: AF (Attenuation Factor): 1,0.

Aerobic Condition (Average Population Constant): 4 : AF : 0,97.

Fitness Factor (FF): Level 0,25 to 0,30: FF: 0,98.

Sum of Ergonomic Index Criticality (SIC): Moderate: FF: 1,0 .

Applying the data to the adjusted formula (Murrell apud Sanders \& McCormick, 1993), we see that the $\mathrm{kcal} / \mathrm{min}$ measure unit in the numerator cancels out with the one in the denominator, and we have:

$$
\mathrm{R}=\frac{240 *[3,67-3,67(0,95)]}{1,5}=\frac{240 *[3,67-3,49]}{1,5}=29,4 \mathrm{~min}
$$

In a raw interpretation we could say that for one particular work activity, considering the set of variables, a person would require a work break of around 30 minutes for every 4 hours of work, which matches physiological studies. It is important to add that other versions of the formula would yield an even smaller rest time. Some applications [12] (QGDH, 2005) do not consider a constant value in the denominator. By doing so, the denominators tend to be higher than our arbitrated constant.

\section{Conclusion}

The introduction of ergonomics in operations management is a truly important industrial planning innovation, with great potential in terms of enhancing productivity and reducing cost.

It preserves overall work conditions on one hand, but it corrects a long time distortion that has been overseen by operations and planning managers throughout the globe. The fact that factory activities is far from being a working bliss, does not allow for mishandling of data regarding more recently improved characteristics of work.

In fact, it sets a paradox: in one hand we are allowing underestimation of human capacity, by considering a wider slot of time for recovering fatigue across the board - as it was being done in our case study due to (outdated) energy consumption assumptions. In counterpart, by not incorporating industrial evolution in the equation, we get an impression of a lesser degree of human performance, since workers are not - theoretically - taking advantage of technological improvements, introduction of new procedures and other sociotechnical breakthroughs.

Regardless what future holds, we must emphasize the need for constant evaluation of our RFad method - or any planning method for that matter - to calibrate it according to shop floor changes. After all, our evaluation model is based on a set of arbitrations, calculations and inferences. As a complex mathematical model, it approaches reality but is not reality itself. It can provide help to decision making, but it cannot always guarantee that right decisions are made. We would recommend advancing from a parameter-based model to a more deterministic one, centered in a customized appropriation of real data. Naturally, it is convenient assess the cost involved in this quest for precision against its real benefits.

The next step - still to be undertaken - in our study is to combine the Rfad method into current planning and programming procedures without much trauma. Two rather conflicting issues arise at this 
moment: a) the impact of eliminating the rates previously considered for the establishment of TAKT times, mainly in terms of pushing its acceptance by factory work committee and b) how to handle economically and budget-wise the operational cost reduction as a consequence of removing the "fatigue factor" from the time sheets and/or replacing it for a more accurate index.

In retrospect, there is one more thing left out for further reflection. By considering scientific facts in building the Rfad methodology, we removed the empirical imposition that has plagued the industrial world since Taylor. We understand our method is still a work in progress, no doubt about it. Yet, regardless of what we will be able to achieve once the Rfad Method is fully consolidated, we are not advocating the plain elimination of the "rule of thumb" when it is derived from good common sense and responsible intuition. Such rigid attitude finds no unanimity in today's organizational world, as we understand the principle of systemic balance. We just want to allow logic to prevail where it "fits" more properly and, maybe, that is why employing Ergonomics in our case made such a difference in the first place. In addition, for who may be inclined to reject our initial findings in the name of a "preservation of worker's right", we understand that there is nothing right in misleading predictions or tempering with data, just like - yet obliviously - several industrial planners are doing right now. We are confident that righteousness will prevail only if we keep working towards correcting that distortion through scientific evidence.

\section{References}

[1] Ästrand,P. \& Rodhal,K. (1977), Textbook of Work Physiology, N.York: McGraw-Hill.

[2• Barnes, Ralph W., (1980). Motion and time study 7th Edition, Design and measurement of work, New York:John Wiley and Sons.
[3] Carayon, P. (1993), Job Design and Job Stress in Office Workers, Ergonomics, 36, May, p. 463-477.

[4] Grandjean, E. (2005) Manual de Ergonomia, Adaptando o trabalho ao homem. Porto Alegre: Bookman.

[5] Keohane, Robert A. (1984), The World Political Economy and the Crisis of Embedded Liberalism, Princeton University Press.

[6] Jackson, A. et. al., Reliability and validity of bioelectrical impedance in determining body composition. Journal Applied of Physiology. v.64. p.529-534, 1988.

[7] Johnson, H. \& Kaplan, R. (1987) Relevance lost: the rise and fall of management accounting, Boston:Harvard Business School Press.

[8] Lung, Yannick (2000): "Is the Rise of Emerging Countries As Automobile Producers an Irreversible Phenomen?" Les Actes du GERPISA 29, 7-18.

[9] Monod, H., (1994), Charge de travail admissible, Paris: Masson.

[10] Moreira, S. (2010), Classroom Notes, Air Force University (UNIFA-Brasil), Rio de Janeiro.

[11] Murrell, K., Bhatia, N., (1969). An industrial experiment in organized rest pauses. Human Factors 11 (2), 167174.

[12] Queensland Government Department of Housing (2005) : Available at http://www.works.qld.gov.au/downloads/tdd/ss_house/maso nry_aust_ergonomic_assess.pdf

[13] Sanders, M. \& McCormick, E., (1993), Human Factors in Engineering and Design, 7th Ed., New York: Mc GrawHill.

[14] Santos, M. (2010) Ergonomic Pattern Mapping - A proposed method for participatory design processes in the workplace. Annals of the 3rd International AHFE Conference.

[15] Silver, Beverly J. (2003): Forces of Labor. Workers' Movement and Globalization Since 1870. Cambridge University Press. 